\title{
Rapid, sensitive and accurate method for determination of Lafutidine hydrochloride in human plasma by RP-HPLC system
}

\author{
Paras P. Vekariya, Hitendra S. Joshi* \\ Department of Chemistry, Saurashtra University, Rajkot - 36005, India \\ *E-mail address: drhsjoshi49@gmail.com
}

\begin{abstract}
Simple and rapid reverse phase high-performance liquid chromatography (RP-HPLC) method was developed and validated using Phenomenex Gemini c18 $(4.6$ × $250 \mathrm{~mm}, 5 \mu)$ reverse phase column for the determination of LAF in human plasma, Solid Phase Extraction (SPE) technique was used for the extraction of analyte, detection was carried out by Photo Diode Array detector at $216 \mathrm{~nm}$. Chromatographic resolution of the LAF was achieved within 4.6 min by using mobile phase Methanol and $5 \mathrm{mM}$ Di-Potassium Hydrogen Phosphate Buffer (pH 9.5) (80:20, v/v), flow rate was $1.0 \mathrm{~mL} / \mathrm{min}$. Calibration curve was linear with correlation coefficient of 0.9996 in the range of $50-1000 \mathrm{ng} / \mathrm{mL}$, Limit of Detection (LOD) and Limit of Quantitation (LOQ) were $10 \mathrm{ng} / \mathrm{mL}$ and $30 \mathrm{ng} / \mathrm{mL}$ respectively, intra and inter-day deviations were lower than $3.92 \%$ and $3.98 \%$ respectively. The overall mean recovery of LAF was $94.57 \%$. No any endogenous constituents were found to interfere at retention time of the analyte. This new RP-HPLC method was successfully validated and may be applied to conduct bioavailability \& bioequivalence studies of LAF.
\end{abstract}

Keywords: HPLC-PDA; Human plasma; Solid phase Extraction

\section{INTRODUCTION}

Lafutidine Hydrochloride (LAF) is 2-(furan-2-ylmethylsulfinyl)-N-[4-[4-(piperidin-1ylmethyl) pyridin-2-yl] oxybut-2-enyl] acetamide refer (Figure 1) (Merck index, 2001) [1]. It belongs to the class of histamine $2(\mathrm{H} 2)$-receptor antagonists and it used in the treatment of peptic ulcer and gastro-oesophageal reflux disease.

It is a second-generation H2-receptor antagonist with an increased action on the gastric mucosal-defensive capacity. It has been shown to exhibit potent gastro protective activity in addition to gastric acid antisecretory effect [2-4]. 


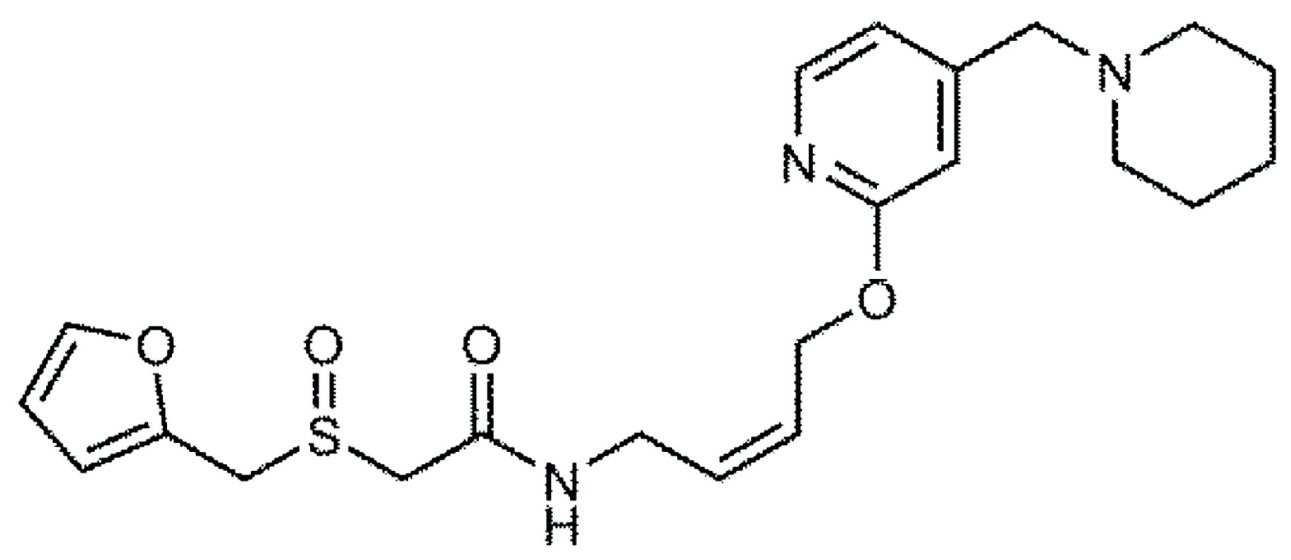

Figure 1. Chemical structure of Lafutidine hydrochloride salt.

It is reported that to cure ulcer H2-receptor therapy was used but after this therapy it was observed that reformation of ulcer was occur rapidly and frequently to prevent such kind of consequence gastroprotactive H2-receptor antagonist drug like famotidine were given along with h2-receptor therapy and LAF is one H2-receptor antagonist [5-7].

There are some methods which reports determination of LAF in human plasma and in serum by high-performance liquid chromatography electro spray ionization mass spectrometry method [8-10], determination of Lafutidine alone and in combination with other drug in Pharmaceutical dosage form [11-13] but as per our literature survey there is no any method have been reported for determination of LAF in human plasma by RP-HPLC using Photo Diode Array detector so here we have developed a rapid sensitive and accurate method for quantitation of Lafutidine in human plasma. As research group is working on analytical development and validation of various bioactive molecule by using sophisticated instrument like HPLC $[14,15]$, so to carry out this work in further direction we have chosen to developed and validate a method to quantify Lafutidine hydrochloride in human plasma.

\section{EXPERIMENTAL}

\section{1. Materials and Reagents}

Pharmacopoeial grade standard of Lafutidine Hydrochloride was received as gift sample by Cadila Pharmaceutical, Ahmedabad. HPLC grade methanol was purchased from Spectrochem Pvt. Ltd., Baroda, water which used in throughout experiment was purified by milli-Q water assembly, analytical grade ammonium acetate was purchased from Spectrochem Pvt. Ltd. and solid phase extraction cartridges (Strata-X) were purchased from Phenomenex, Hyderabad. HPLC column Gemini C18 $(4.6 \times 250 \mathrm{~mm}, 5 \mu \mathrm{m})$ was purchased from Phenomenex.

\section{2. Instrumentation}

The chromatographic system used to perform development and validation of this assay method was comprised of LC-10ATvp binary pump, SPD-M10Avp photo-diode Array detector and Rheodyne manual injector model $7725 \mathrm{i}$ with $20 \mu 1$ loop (Shimadzu, Kyoto, Japan), connected to a multi-instrument data acquisition and data processing system (LC Solution, Shimadzu). 


\section{3. Biological samples}

Blank human plasma for the development and validation of the method were obtained from government recognise laboratory.

\section{4. Chromatographic Conditions}

Chromatographic analysis was performed on a reverse phase HPLC Phenomenex Gemini C18 $(4.6 \times 250 \mathrm{~mm}, 5 \mu \mathrm{m})$ column, mobile phase consisted of Methanol and $5 \mathrm{~m} \mathrm{M}$ Di-Potassium Hydrogen Phosphate Buffer ( $\mathrm{pH} 9.5)$ (80:20, v/v). Flow rate was adjusted to 1.0 $\mathrm{ml} / \mathrm{min}$. retention time of analyte was $7.6 \mathrm{~min}$, injection volume was $20 \mu \mathrm{L}$ and detection was performed at $216 \mathrm{~nm}$.

\section{5. Preparation of stock solution and spiked plasma sample}

The stock solution of LAF were prepared in methanol at concentration of $1.0 \mathrm{mg} / \mathrm{ml}$ working solution of $50 \mu \mathrm{g} / \mathrm{ml}$ were prepared by appropriately diluting the stock solution of LAF with 50:50 methanol water. Working solution of LAF was used to prepare the spiking stock solution for preparation of nine point calibration curve $(50-1000 \mathrm{ng} / \mathrm{ml})$ and quality control (QC) samples at three concentration level LQC (50 ng/mL), MQC (500 ng/mL) and HQC $(1000 \mathrm{ng} / \mathrm{ml})$ all stock and working solution were stored in refrigerator (at $\left.2-8{ }^{\circ} \mathrm{C}\right)$ when not in use. The spiked plasma sample was prepared by adding $25 \mu \mathrm{l}$ of respective spiking stock solution in $475 \mu 1$ of Blank plasma.

\section{6. Sample preparation and extraction procedure}

Extraction was performed by solid phase extraction procedure as described below, 0.5 $\mathrm{ml}$ aliquot of the spiked plasma sample was pipetted into $10 \mathrm{ml}$ glass centrifuge tube and mixed with $250 \mu \mathrm{l}$ of ammonium acetate buffer ( $\mathrm{pH} 4.5$ ), vortexed thoroughly, mixture was loaded in to strata-x cartridge which was pre-conditioned by $1 \mathrm{ml}$ methanol followed by $2 \mathrm{ml}$ water, than cartridge was washed by $1 \mathrm{ml}$ water for two time after that cartridge was transferred into clean test tube and the analyte was eluted with $0.5 \mathrm{ml}$ methanol from which $20 \mu \mathrm{L}$ volume is injected into HPLC system.

\section{METHOD VALIDATION}

The validation was executed as per 'Guidance for Industry: Bio analytical Method Validation' from the United States Food and Drug Administration [16].

\section{1. Selectivity}

The selectivity of the method was performed to ensure absolute separation of LAF from the biological endogenous components of the human plasma. Selectivity was carried out by analysing seven different lots of blank human plasma by solid phase extraction procedure.

\section{2. Linearity}

Five standard curves of nine different concentration standards (50-1000 ng/ml) and two blank samples have been assayed to achieve calibration curve but only nine concentration standards were included in the calibration curve whereas blank sample were used to check interference and contamination. 


\section{3. Precision \& Accuracy}

Intra-day and Inter-day precision and accuracy were evaluated by five spiked samples analyzed at three level of quality control samples $(50,500$ and $1000 \mathrm{ng} / \mathrm{mL})$ of LAF. Intra -day precession and accuracy was determined by repeated analysis of five spiked samples of LAF at each QC level. Inter-day precession and accuracy were determined by repeated analysis of three consecutive days ( 5 series per day). The concentration of each sample was determined using standard curves prepared and analysed on same day.

\section{4. Matrix effect}

To evaluate the effect of endogenous contribution of different source of blank plasma in the measurement of the analyte the matrix effect was checked. Matrix effect was evaluated by comparing peak area of extracted sample using five different lots of blank human plasma in triplicate at two concentration level of QC (50 and $1000 \mathrm{ng} / \mathrm{ml}$ ) samples, percentage deviation and relative error were calculated to check interference of matrix effect on the analyte concentration.

\section{5. Recovery}

Peak area from unextracted analyte with those of extracted analyte determined recovery. Percentage recovery of LAF was determined by comparing mean area of five replicates each of extracted quality control sample with mean area of freshly prepared unextracted quality control samples which were prepared by spiking blank extracts with respective spiking solution.

\section{RESULT AND DISCUSSION}

\section{1. Sample preparation}

To accelerate drug dissociation of analyte from plasma different buffers were tried, but with $25 \mathrm{mM}$ ammonium acetate $(\mathrm{pH} 4.5)$ recovery and response were found better so it was added to plasma sample and methanol was used as eluent.

\section{2. Separation}

Different mobile phase were investigated using methanol, acetonitrile and ammonium acetate in various proportions, after several trials Methanol and $5 \mathrm{mM}$ Di- Potassium Hydrogen Phosphate Buffer ( $\mathrm{pH}$ 9.5) (80:20, v/v) mobile phase was finalised. Flow rate selection was based on peak parameters height, asymmetry, tailing, and baseline drift and run time and set at $1.0 \mathrm{~mL} / \mathrm{min}$. The retention time for the investigated drug was found at $7.6 \mathrm{~min}$ and runtime was $15 \mathrm{~min}$. Different columns have been tested, with minimal effect on the resolution of the analyte Phenomenex Gemini C18 $(4.6 \times 250 \mathrm{~mm}, 5 \mu \mathrm{m})$ column have been finalised because of its demonstrated smoothness and reproducibility in this method.

The optimum wavelength for detection of analyte was $216 \mathrm{~nm}$, at which much better detector response was obtained. For the estimation of LAF a sharp and symmetrical peak was obtained with good baseline, which assists the accurate measurement of the peak area.

\section{3. Assay selectivity}

Seven blank samples were assayed to examine selectivity of the method therefore it was expected that area of clinical samples would not be prevented by interference peak in this method. Representative chromatogram of blank sample and LLOQ sample are shown in Figure 2. There was no interference of endogenous peak observed at the retention time of LAF results of selectivity are enumerated in Table 1. 

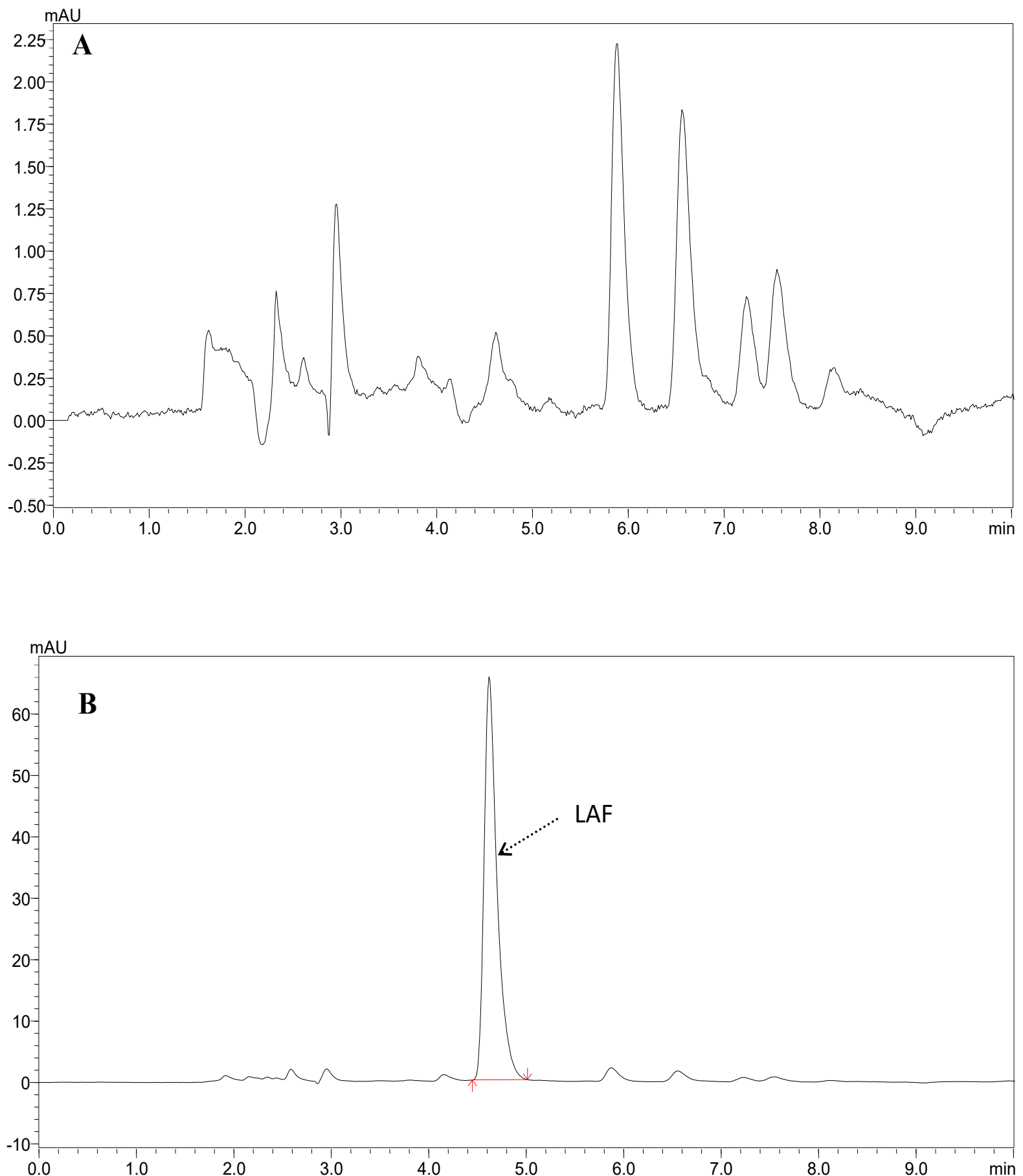

Figure 2. HPLC-PDA chromatograms of blank plasma sample and LLOQ $(1.0 \mu \mathrm{g} / \mathrm{mL})$ standard (A); chromatogram of extracted blank plasma (B); Chromatogram of extracted LLOQ sample spiked with $1.0 \mu \mathrm{g} / \mathrm{mL}$ of calibration standard. 
Table 1. Summary of selectivity experiment results.

\begin{tabular}{|c|c|}
\hline Sample name & AREA \\
\hline LLOQ (50 NG) & 285621 \\
\hline LLOQ (50 NG) & 276789 \\
\hline LLOQ (50 NG) & 279521 \\
\hline LLOQ (50 NG) & 258952 \\
\hline LLOQ (50 NG) & 290014 \\
\hline MEAN & 278179 \\
\hline Blank plasma lot no. & AREA \\
\hline LOT-1 & 0 \\
\hline LOT-2 & 0 \\
\hline LOT-3 & 0 \\
\hline LOT-4 & 0 \\
\hline LOT-5 & 0 \\
\hline LOT-6 & 0 \\
\hline LOT-7 & 0 \\
\hline LOT-8 & 0 \\
\hline
\end{tabular}

\section{4. Linearity}

Five calibration curves were assayed as mentioned in section 3.2. The linearity of the method was evaluated by 9 point calibration curve in the concentration range of 50-1000 $\mathrm{ng} / \mathrm{ml}$ calibration plot is shown in Figure 3.

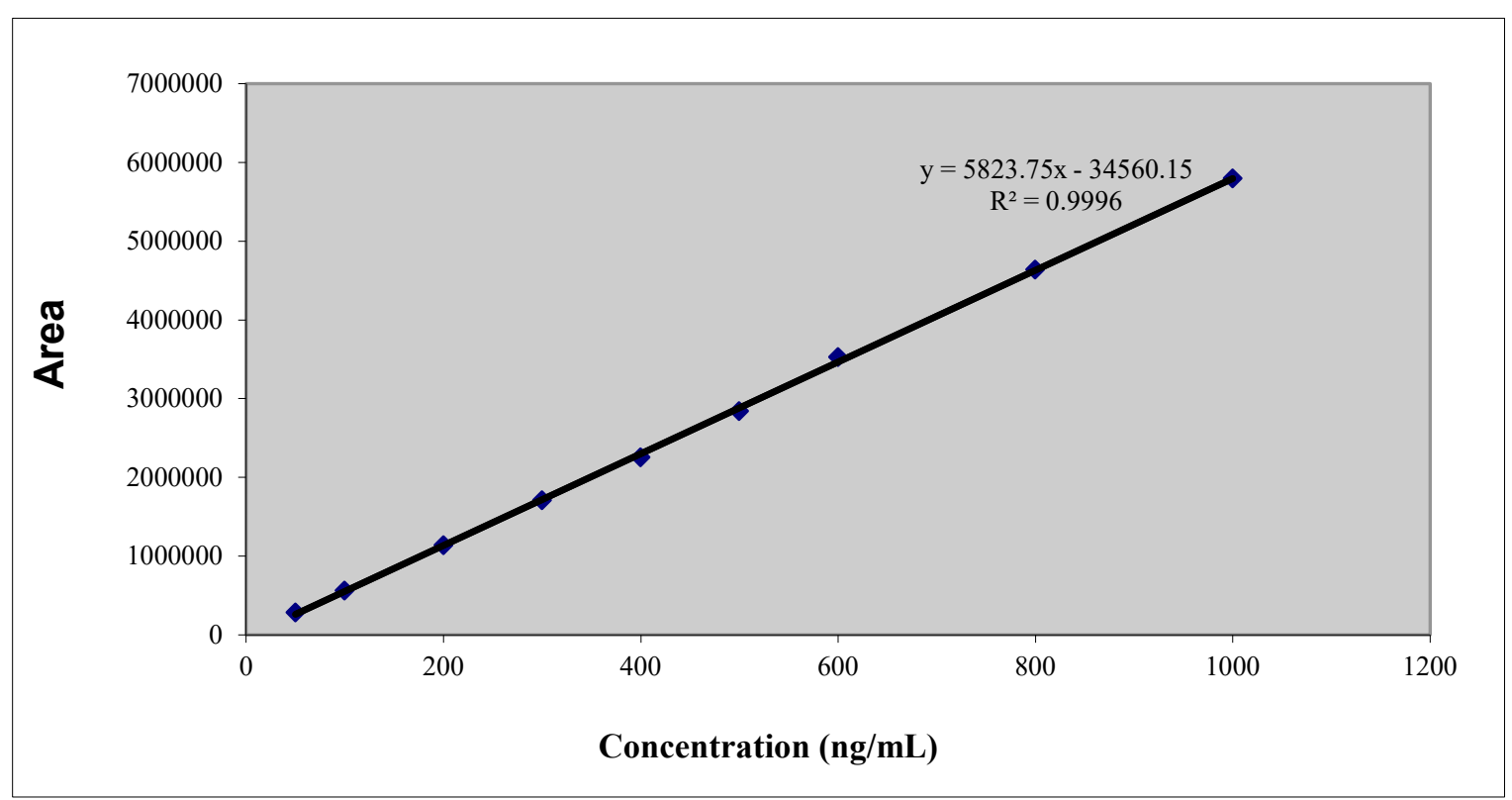

Figure 3. Calibration curve of Lafutidine Hydrochloride.

All calibration curves were linear over the range of 50-1000 ng/ml. correlation coefficient was $\geq 0.9996$ Calibration curve was determined by peak area versus concentration. 
The mean slope of calibration curves was 5832.75 and mean intercept was -34560.15 Concentration of analyte was calculated by using mean calculation formula $\mathrm{Y}=\mathrm{MX}+\mathrm{C}$ where $\mathrm{M}=$ Slope and $\mathrm{C}=$ Intercept.

Data of calibration curves is given in Table 2 and Table 3.

Table 2. Back calculated concentration of calibration standards from respective calibration curves.

\begin{tabular}{|c|c|c|c|c|c|c|c|c|c|}
\hline \multirow{2}{*}{ Linearity } & \multicolumn{8}{|c|}{ Lafutidine conc. (ng/ml) } \\
\cline { 2 - 10 } & 50 & 100 & 200 & 300 & 400 & 500 & 600 & 800 & 1000 \\
\hline 1 & 53.75 & 102.34 & 200.30 & 306.67 & 381.41 & 493.15 & 602.22 & 793.48 & 998.77 \\
\hline 2 & 54.98 & 104.27 & 201.64 & 296.22 & 396.12 & 495.25 & 605.83 & 788.38 & 1011.97 \\
\hline 3 & 54.35 & 100.76 & 198.97 & 295.40 & 393.44 & 490.95 & 623.15 & 811.80 & 979.27 \\
\hline 4 & 52.46 & 100.74 & 199.81 & 297.71 & 394.99 & 491.09 & 615.89 & 811.18 & 994.46 \\
\hline 5 & 53.68 & 99.89 & 199.81 & 295.42 & 395.56 & 492.80 & 603.93 & 801.06 & 1014.67 \\
\hline Mean & 53.84 & 101.60 & 200.11 & 298.29 & 392.30 & 492.65 & 610.21 & 801.18 & 999.83 \\
\hline Accuracy & 107.69 & 101.60 & 100.05 & 99.43 & 98.08 & 98.53 & 101.70 & 100.15 & 99.98 \\
\hline SD & 0.93 & 1.73 & 0.98 & 4.78 & 6.17 & 1.76 & 8.97 & 10.44 & 14.32 \\
\hline$\%$ CV & 1.73 & 1.71 & 0.49 & 1.60 & 1.57 & 0.36 & 1.47 & 1.30 & 1.43 \\
\hline
\end{tabular}

Table 3. Parameter corresponding to liner regression obtained from calibration curve of LAF.

\begin{tabular}{|c|c|c|c|}
\hline Calibration Curve & Slope & Intercept & $\begin{array}{c}\text { Correlation } \\
\text { Coefficient }\end{array}$ \\
\hline 1 & 5787.17 & -23116.70 & 0.9997 \\
\hline 2 & 5827.79 & -26340.88 & 0.9998 \\
\hline 3 & 5819.10 & -41906.04 & 0.9989 \\
\hline 4 & 5843.58 & -30890.45 & 0.9997 \\
\hline 5 & 5886.14 & -50546.69 & 0.9999 \\
\hline Mean & 5832.75 & -34560.15 & 0.9996 \\
\hline
\end{tabular}

\section{5. Sensitivity}

Sensitivity of the analytical method can be measured by calculating Limit of Detection and Quantification (LOD and LOQ) of analytical method. LOD and LOQ were estimated in accordance with the baseline to noise ratio, it should be 3 and 10 time higher than the blank plasma sample. LOD and LOQ were estimated to be $10 \mathrm{ng} / \mathrm{mL}$ and $40 \mathrm{ng} / \mathrm{mL}$ respectively, a representative chromatogram of LOD and LOQ is given in Figure 4. 

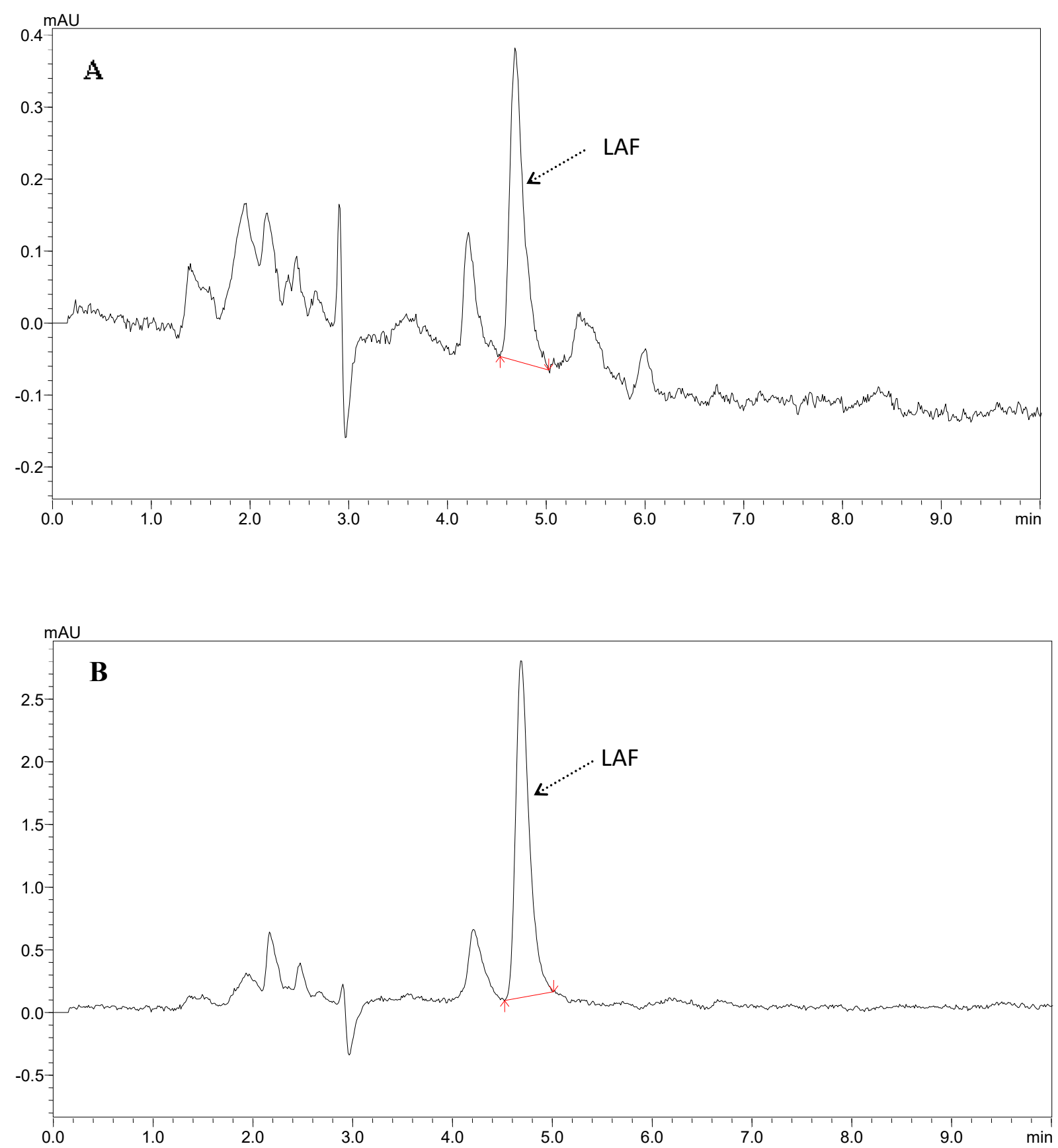

Figure 4. HPLC-PDA chromatogram of LOD and LOQ sample (A); Chromatogram of LOD sample (B); Chromatogram of LOQ sample.

\section{6. Precision and accuracy}

As shown in Table 4 Intra-day deviation from nominal concentration was $\leq 4.46$ and intra-day precision was $\leq 3.92$. Inter-day deviation from nominal concentration was $\leq 5.12$ and inter-day precision was $\leq 3.98$. 
Table 4. Intra- and Inter-day precision and accuracy of the method for determination of LAF.

\begin{tabular}{|c|c|c|c|c|c|c|}
\hline \multirow[b]{2}{*}{$\begin{array}{l}\text { Added conc. } \\
\qquad(\mathrm{ng} / \mathrm{mL})\end{array}$} & \multicolumn{3}{|c|}{ Intra-Day } & \multicolumn{3}{|c|}{ Inter-Day $^{\mathrm{N}}$} \\
\hline & $\begin{array}{c}\text { Mean } \\
\text { calculated } \\
\text { conc. } \\
(\mathrm{ng} / \mathrm{mL})\end{array}$ & $\%$ RSD & $\% \mathrm{RE}$ & $\begin{array}{c}\text { Mean } \\
\text { Calculated } \\
\text { conc. } \\
(\mathrm{ng} / \mathrm{mL})\end{array}$ & $\% \mathrm{RSD}$ & $\% \mathrm{RE}$ \\
\hline 50 & 52.23 & 3.92 & 4.46 & 52.29 & 3.98 & 4.57 \\
\hline 500 & 499.77 & 1.32 & -0.05 & 496.89 & 1.15 & -0.62 \\
\hline 1000 & 1003.09 & 0.86 & 0.31 & 1051.19 & 3.97 & 5.12 \\
\hline
\end{tabular}

${ }^{\mathrm{N}}$ For Inter -Day (samples injected were 5 series per day).

\section{7. Matrix effect}

Results of matrix effect are given in Table 5. Percentage deviation and relative error of the injected samples at LQC level was $\leq 3.81 \%$ and $\leq 7.27 \%$ respectively and at MQC level Percentage deviation and relative error was $\leq 3.50 \%$ and $\leq 3.26 \%$ respectively. Results indicate that there is no considerable endogenous contribution from blank plasma for the measurement of analyte.

Table 5. Result of matrix effect experiment of LAF.

\begin{tabular}{|c|c|c|c|c|c|c|c|}
\hline \multicolumn{2}{|c|}{} & \multicolumn{3}{c|}{50 ng/mL } & \multicolumn{3}{c|}{1000 ng/mL } \\
\cline { 2 - 8 } & Mean & $\%$ RSD & \% RE & Mean & $\%$ RSD & $\%$ RE \\
\hline A-1 & 3 & 53.63 & 1.00 & 7.27 & 1021.10 & 0.95 & 2.11 \\
\hline A-2 & 3 & 51.61 & 2.22 & 3.21 & 990.84 & 3.50 & -0.92 \\
\hline A-3 & 3 & 51.60 & 2.24 & 3.20 & 1032.61 & 0.39 & 3.26 \\
\hline A-4 & 3 & 49.87 & 3.81 & -0.26 & 1018.45 & 0.88 & 1.84 \\
\hline A-5 & 3 & 49.77 & 3.30 & -0.46 & 1012.46 & 1.79 & 1.25 \\
\hline
\end{tabular}

\section{8. Extraction recovery}

The extraction recovery determined for LAF was consistent, precise and reproducible. As per result given in Table 6. Mean recoveries of the three concentration levels $(50,500$ and $1000 \mathrm{ng} / \mathrm{mL}$ ) were $93.18,96.08$ and $94.45 \%$ respectively, whereas the mean recovery between QC level is $94.57 \%$. 
Table 6. Summary of absolute recovery results of LAF from $0.5 \mathrm{ml}$ of plasma.

\begin{tabular}{|c|c|c|c|}
\hline & $\mathbf{5 0} \mathbf{~ n g} / \mathbf{m L}$ & $\mathbf{5 0 0} \mathbf{~ n g} / \mathbf{m L}$ & $\mathbf{1 0 0 0} \mathbf{~ n g} / \mathbf{m L}$ \\
\hline $\begin{array}{c}\text { \% Mean Recovery } \\
\text { Within QC Level }\end{array}$ & $93.18 \%$ & $96.08 \%$ & $94.45 \%$ \\
\hline \% RSD & $1.56 \%$ & $1.51 \%$ & $1.54 \%$ \\
\hline $\begin{array}{c}\text { \% Mean Recovery } \\
\text { Between QC Level }\end{array}$ & \multicolumn{3}{|c|}{$94.57 \%$} \\
\hline SD & 1.45 \\
\hline \% CV & $1.56 \%$ \\
\hline
\end{tabular}

\section{9. Dilution integrity}

The upper concentration limit of LAF can be extended to $2000 \mathrm{ng} / \mathrm{ml}$ with acceptable percentage deviation and relative error of $15 \%$ by 2 -fold or 4 -fold dilution with blank human plasma. The Results demonstrate percentages deviation and relative error at 2 fold dilution was $\leq 3.59 \%$ and $\leq 2.07 \%$ and for 4 fold dilution deviation and relative error was $\leq 4.29 \%$ and $\leq 2.80 \%$ results are demonstrated in Table 7 which shows that dilution of sample dose not effect on the precession and accuracy of the result obtained by this method so the clinical sample which are above the limit of quantitation can be analysed accurately even if dilution is up to 4 fold.

Table 7. Results obtained by dilution integrity experiment of LAF.

\begin{tabular}{|c|c|c|c|c|c|}
\hline set & Dilution & $\begin{array}{c}\begin{array}{c}\text { Dilution } \\
\text { factor }\end{array} \\
\end{array}$ & $\begin{array}{c}\text { Obtain } \\
\text { conc. }\end{array}$ & $\% \mathrm{RE}$ & $\%$ RSD \\
\hline \multirow{5}{*}{2000} & $1 / 2$ & 2 & 2009.45 & 0.47 & \multirow{5}{*}{2.07} \\
\hline & $1 / 2$ & 2 & 1928.29 & -3.59 & \\
\hline & $1 / 2$ & 2 & 1990.20 & -0.49 & \\
\hline & $1 / 2$ & 2 & 2036.94 & 1.85 & \\
\hline & $1 / 2$ & 2 & 1968.37 & -1.58 & \\
\hline \multirow{5}{*}{2000} & $1 / 4$ & 4 & 1914.30 & -4.29 & \multirow{5}{*}{2.80} \\
\hline & $1 / 4$ & 4 & 1987.22 & -0.64 & \\
\hline & $1 / 4$ & 4 & 2013.10 & 0.66 & \\
\hline & $1 / 4$ & 4 & 1934.68 & -3.27 & \\
\hline & $1 / 4$ & 4 & 2050.79 & 2.54 & \\
\hline
\end{tabular}




\section{10. Stability}

Table 8 summarizes stability experiments which are bench top 24 hour at room temperature, post extraction (at $4-8{ }^{\circ} \mathrm{C}$ after extraction), freeze thaw stability(three cycle), long-term stability for 30 days (stored at $-20^{\circ} \mathrm{C}$ ) and post preparative stability data of LAF. All the results showed the stability behaviour during these tests and there were no stability related problems occurred during the validation and stability testing. The stability of working solutions was tested and on the basis of the results these solutions were stable till $6 \mathrm{~h}$.

Table 8. Result of Stability experiment of LAF.

\begin{tabular}{|c|c|c|c|c|c|}
\hline $\begin{array}{c}\text { Stability } \\
\text { Experiment }\end{array}$ & QC level & $\begin{array}{c}\text { Spiked conc. } \\
\text { (ng/mL) }\end{array}$ & $\begin{array}{c}\text { Comparison } \\
\text { sample }\end{array}$ & $\begin{array}{c}\text { Stability } \\
\text { sample }\end{array}$ & $\begin{array}{c}\% \\
\text { Change }\end{array}$ \\
\hline \multirow{2}{*}{ Bench top } & LQC & 50 & 52.34 & 52.10 & -2.24 \\
\cline { 2 - 6 } & HQC & 1000 & 999.67 & 1020.88 & 2.12 \\
\hline \multirow{2}{*}{\begin{tabular}{c} 
Process \\
\cline { 2 - 6 }
\end{tabular}} & LQC & 50 & 51.34 & 53.23 & 3.67 \\
\cline { 2 - 6 } Freez and \\
\cline { 2 - 6 } Thaw & LQC & 1000 & 987.96 & 995.56 & 0.77 \\
\cline { 2 - 6 } & HQC & 1000 & 1012.33 & 995.41 & -1.67 \\
\hline \multirow{3}{*}{\begin{tabular}{c} 
Lomg term \\
\cline { 2 - 6 }
\end{tabular}} & LQC & 50 & 48.54 & 53.17 & 9.54 \\
\cline { 2 - 6 } & HQC & 1000 & 985.47 & 1005.52 & 2.03 \\
\hline
\end{tabular}

Note: Three samples were injected at each level

The bench top stability of LAF was investigated at LQC and HQC levels this revealed that LAF in plasma is stable for at least $6 \mathrm{hrs}$ at room temperature and $24 \mathrm{hrs}$ at auto sampler with mean percentages of $\leq 2.24 \%$ and $\leq 2.12$ respectively. It was confirmed that repeated freeze and thawing of plasma sample spiked with LAF at LQC and HQC level did not affect the stability of Lafutidine with mean percentage of $\leq 4.31 \%$ and $\leq 1.67 \%$. Long term stability of the LAF in plasma at $-20^{\circ} \mathrm{C}$ was also performed for 80 days at LQC, MQC and HQC level with mean percentages change of LAF $9.54 \%, 1.58 \%$ and $2.08 \%$. The results of the stability are enumerated in Table 9. The above results indicate that LAF is stable enough to be analysed using this assay method.

\section{CONCLUSION}

We have developed a suitable method to quantify Lafutidine hydrochloride in human plasma by solid phase extraction procedure. The method is simple, sensitive, specific and reproducible and may be used in bioavailability and bioequivalence study. 


\section{ACKNOWLEDGEMENTS}

The authors are thankful of Cadila pharmaceutical Ltd., Ahmedabad For supply us the Lafutidine Hydrochloride, facilities \& grants given under UGC- Special Assistance Program Department Research Support (SAP-DRS), Department of Science \& Technology (DST) New Delhi, Fund For Improvement of Science \& Technology (FIST), National Facility for Drug Discovery and Department of Chemistry, Saurashtra University, Rajkot - 360 005 (INDIA) for providing analytical facilities.

\section{References}

[1] The Merck Index, 2001. An encyclopedia of Chemicals, Drugs and Biologicals, Thirteenth Edition, Merck Research Laboratories division of Merck and Co., Inc. Whitehouse Station, NJ, USA, 1263.2., 5362: 957.

[2] T. Shimatani, M. Inoue, T. Kuroiwa, J. Xu, M. Nakamura, Digestive Diseases Science 51(2006) 114-20.

[3] H. Sato, K. Kawashima, M. Yuki, H. Kazumori, M. Rumi, C. Ortega, The Journal of Laboratory and Clinical Medicine 141 (2003) 102-105.

[4] H. Toh, T. Aito, M. Akeyama, Biological Pharmaceutical Bulletin 25 (2002) 379-382.

[5] H. Ajioka, N. Matsuura, H. Miyake, Inflammopharmacology 10 (2002) 483-493.

[6] K. Nagahama, M. Yamato, S. Kato, K. Takeuchi, Journal of Pharmacological Sciences 93(2003) 55-61.

[7] H. Iida, M. Inamori, Y. Nozaki, H. Endo, K. Hosono, T. Akiyama, BMC Gastroenterology 9 (2009) 52.

[8] L. Wu, Z. Zhang, Y. Tian, W. Li, F. Xu, Y. Chen, Journal of Mass Spectrometry 40 (2005) 1637-1643.

[9] W. Chen, Y. Liang, H. Li, Y. Xiong, X. Liu, G. Wang, Journal of Pharmaceutical and Biomedical Analysis 41 (2006) 256-60.

[10] K. Jadhav, D. Dhamecha, S. Ghadlinge, G. Asnani, M. Patil, ISRN Analytical Chemistry (2012) 1-4.

[11] M. Sumithra, P. Sundaram, K. Srinivasulu, International Journal of Chemistry 3 (2011) 1403-1407.

[12] M. Jagadeeswaran, N. Gopal, B. Jayakar, T. Sivakumar, Global Journal of Pharmacology 6 (2012) 60-64.

[13] R. Parekh, P. Patel, C. Patel, H. Patel, International Journal of Drug Development \& Research 4 (2012) 325-329.

[14] P. Vekariya, H. Joshi, ISRN Spectroscopy (2013) 1-6.

[15] G. Pandya, H. Joshi, Der Pharmacia Sinica 4 (2013) 145-152.

[16] US Department of Health and Human Services, Food and Drug Administration, Center for Drug Evaluation and Research (CDER). Guidance for Industry, Bioanalytical Method Validation, May 2001. 